\title{
ESCOLAS DO RIO DE JANEIRO OCUPADAS: FACES DE UMA PEDAGOGIA MILITANTE
}

\section{OCUPATED SCHOLLS OF RIO DE JANEIRO: FACES OF A MILITANT PEDAGOGY}

\author{
BASTOS, Rafael ${ }^{1}$ \\ MARINHO, Viviane ${ }^{2}$
}

\begin{abstract}
RESUMO
Este estudo tem com objeto as ocupações de escolas da rede básica de educação do estado do Rio de Janeiro. As metodologias utilizadas foram: observação participante; análises das representações sociais; aplicação de questionários e entrevistas. A perspectiva dialética materialista também é mobilizada. As questões mais importantes constatadas são: debates sobre feminismo, diversidade sexual e respeito às minorias; o protagonismo feminino nas atividades de liderança; autogestão; questionamento do modelo de gestão escolar atual e luta pela gestão democrática; questionamento sobre a democracia contemporânea e seus limites para a juventude; crítica ao sistema político partidário vigente; identificação com o espaço público; participação social; revisão do currículo. Verificamos que as ocupações foram experiências significativas para estes sujeitos, na perspectiva da construção da identidade coletiva, da participação política, do protagonismo jovem, que por meio de uma pedagogia militante redimensionam sentidos na formação escolar.
\end{abstract}

Palavras-Chave: Ocupações; Escola; Estudantes; Participação política; Pedagogia militante.

\section{ABSTRACT}

This study has as object the occupation of schools of the primary education system in the state of Rio de Janeiro. The methodologies used were: participant observation; analysis of social representations; application of questionnaires and interviews. The materialistic dialectical perspective was also mobilized. The most important issues identified were: debates on feminism, sexual diversity and respect for minorities; the female prominence in leadership activities; self-management; questioning of the current school management model and struggle for democratic management; questioning about contemporary democracy and its limits for youth; criticism of the party political system in force; identification with the public space; social participation; review of the curriculum. We verified that the occupations were significant experiences for these subjects, in the perspective of the construction of a collective identity, of political participation, of the prominence of youths who, through a militant pedagogy, reconfigure meanings in school education.

KeYwORDS: Ocupations; Scholl; Students; Political participation, Militant pedagogy.

\footnotetext{
${ }^{1}$ Professor Adjunto da Universidade do Estado do Rio de Janeiro e da Universidade Católica de Petropolis; Doutor em Políticas Públicas e Formação Humana (UERJ). e-mail: rafaelbastosoliveira@yahoo.com.br

2 Professora da Universidade Federal do Rio de Janeiro; Doutora em Alimentação, Nutrição e Saúde (UERJ). e-mail: vivianemarinho@nutricao.ufrj.br
} 
DOI: $10.12957 / \mathrm{e}-m o s a i c o s .2017 .30265$

\section{INTRODUÇÃO}

A nossa aproximação com este objeto de estudo se deu por meio das pesquisas inseridas no Grupo de Pesquisa em Educação, Estado, Sociedade Civil e Participação Política (GPESP), que discute experiências de participação política e construção da gestão democrática da escola no estado do Rio de Janeiro. O grupo mantém vínculo com a Universidade do Estado do Rio de Janeiro, Universidade Federal do Rio de Janeiro e com a Universidade Católica de Petrópolis. Este grupo se insere no campo de estudos qualitativos (em especial de metodologias etnográficas e sociológicas) sobre algumas experiências de participação da sociedade civil, do município de Petrópolis e região metropolitana do Rio de Janeiro, na construção de políticas públicas de educação. A análise contempla a participação social em diversas esferas deste campo das políticas públicas, a saber: no espaço da gestão escolar, nos conselhos sociais (tanto da escola, quanto no conselho municipal de educação, assim como nas conferências nacionais) e em movimentos sociais. São consideradas principalmente as categorias: democracia, ideologia, organização política, projeto de educação, gestão democrática da educação, financiamento da educação e projeto de país.

No levantamento de experiências escolares que promovem uma gestão democrática em estreita parceria com a comunidade (em Petrópolis e região metropolitana do Rio de Janeiro), nos deparamos, nos meses de março a junho de 2016, com o processo de ocupações de escolas públicas da rede básica estadual do Rio de Janeiro. Como já vínhamos teorizando sobre a categoria democracia, verificamos que as ocupações revelavam uma face radicalizada ${ }^{3}$ dessa experiência, necessitando uma análise empírica aprofundada e teorização sobre este fenômeno social contemporâneo, que já tinha ocorrido no estado de São Paulo e até os dias recentes vem se repetindo em todo território nacional, como os casos de Minas Gerais e Goiás. Desde então voltamos nossas atenções para investigar esses acontecimentos.

Com este ensaio procuramos compreender o movimento de ocupação de escolas Brasil em seu contexto histórico-político. Esse movimento em curso entre os anos de 2015 e 2016 é um importante marco na organização e forma de reivindicação dos movimentos sociais, em especial se comparada essa tática com outras formas de luta que vieram se mostrando menos eficientes a nível nacional.

Para tal, realizamos uma breve introdução sobre as ocupações estudantis brasileiras para contextualizar o cenário em que se inserem as ocupações ocorridas no Estado do Rio de Janeiro no ano de 2016, alvo principal de nossa investigação.

O movimento de ocupações de escolas no Brasil tem como marcos alguns fatos históricos que foram desencadeadores dessa tática de resistência. Podemos destacar o mês de setembro de 2015 como um importante momento para esse levantamento histórico. Nesse período, em São Paulo, eram anunciadas medidas do

\footnotetext{
${ }^{3} \mathrm{~A}$ radicalidade que nos referimos remete às origens da idéia de democracia na Grécia antiga, no qual a liberdade de exercer a oratória, convencer, ser convencido e dar os rumos da polis era uma tarefa a ser feita cotidianamente, diretamente e pelos homens livres.
} 


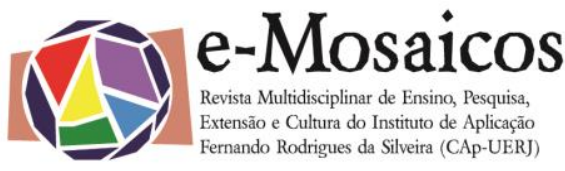

DOI: $10.12957 /$ e-mosaicos.2017.30265

governo do estado, que através de uma proposta de travestida de reorganização escolar, sinalizava o fechamento de quase cem escolas. Além disso, o projeto apresentado traria impacto na vida de um milhão de alunos que seriam transferidos de unidade educacional para que as escolas passassem a atender exclusivamente um ciclo educacional (ensino fundamental I, ensino fundamental II e ensino médio). Essas medidas, completamente verticais e arbitrárias, não foram construídas com os setores interessados e diretamente impactados por elas, quais sejam, a comunidade escolar como um todo (CAMPOS, MEDEIROS e RIBEIRO, 2016).

Esse foi um dos fatores de estopim para o início das manifestações contra a reorganização escolar. Manifestações que começaram nas ruas - entre setembro e novembro de 2016 - e que se voltaram para os espaços que se queria defender: a própria escola. As ocupações das escolas de São Paulo se iniciaram em 08 de novembro de 2015 e chegaram ao ápice no início do mês de dezembro, quando mais de duzentas escolas encontravam-se ocupadas (CAMPOS, MEDEIROS e RIBEIRO, 2016).

Dados difundidos na grande mídia apontam que a história construída em São Paulo inspirou diversos estudantes de outros estados a ocupar suas escolas, mobilizados por pautas universais, mas também por pautas locais. A mobilização através de ocupações atingiu 19 estados e quase mil escolas em todo o Brasil, em outubro de 2016 (GLOBO, 2016; EL PAIS, 2016). Os estudantes ocupantes agora se mobilizam em especial contrariamente à Proposta de Emenda Constitucional 55/2016 - que versa sobre o congelamento dos gastos públicos em várias áreas, como saúde e educação, por vinte anos; e à Medida Provisória 746/2016 de reestruturação do ensino médio - que flexibiliza os currículos e, segundo diversos críticos à medida, pode ter como resultados o aprofundamento das desigualdades e o aumento da evasão escolar.

O objeto de estudo aqui apresentado trata de algumas experiências das ocupações de escolas públicas estaduais, da rede básica de educação do estado do Rio de Janeiro. Durante aproximadamente quatro meses - entre os meses de março e junho - os estudantes da rede iniciaram um processo de ocupações das escolas com objetivo de reivindicar diversas pautas.

Esse movimento surge em uma conjuntura de crise política e econômica a nível nacional e também perante uma grave crise financeira da gestão pública do estado do Rio de Janeiro, que culminou com o decreto de calamidade pública por parte do governador em exercício Francisco Dorneles (Decreto 45.692/16). Em reação a esse contexto, diversas categorias fizeram greves e manifestações, como os educadores da rede estadual de educação básica e outros.

As metodologias utilizadas nesta pesquisa foram: observação participante, realizada em quatro escolas, em diferentes espaços geográficos do estado e distintas regiões administrativas da rede estadual de educação; também foi realizada análise das representações sociais dos discentes, por meio de aplicação de questionários e através de consulta a páginas na internet; também entrevistamos algumas lideranças-chave das escolas. 
As escolas visitadas foram nos municípios de Petrópolis (região serrana do estado Rio de Janeiro), Nova Iguaçu (região da baixada fluminense) e na própria capital fluminense, na região norte.

Em Petrópolis visitamos o Colégio Estadual Dom Pedro II, um dos mais tradicionais da cidade. Segundo os alunos foi a primeira vez que uma escola foi ocupada na cidade. Em Nova Iguaçu, foi o Instituto de Educação Rangel Pestana. Instituição reconhecida na região e que forma professores. Na cidade do Rio de Janeiro fomos até as ocupações do Colégio Estadual Paulo Freire, no bairro do Cachambi (subúrbio da cidade) e o Colégio Estadual Compositor Luiz Carlos da Vila (bairro de Manguinhos, também no subúrbio).

Esta última foi inaugurada em 2009, como fruto do Programa de Aceleração do Crescimento (PAC) e foi a primeira obra deste projeto inaugurado na cidade. Contou, na ocasião da abertura, com participação do ex-presidente Lula. A escola tem uma estrutura muito interessante, com piscina, inclusive, além de quadros interativos e demais equipamentos. Porém vem sofrendo com depredação do patrimônio. A piscina virou até mesmo foco de dengue devido à ausência de manutenção.

Nas escolas visitadas identificamos que os alunos se dividiram em comissões, responsáveis por tarefas específicas como comunicação, alimentação, atividades, entre outras. Em diversos casos foi possível verificar o apoio da comunidade local para manutenção das ocupações.

Foi corriqueiro o apoio de pais de alunos também, além de uma parte importante da academia e de artistas, como Marisa Monte, Chico Santa Cruz e etc. Os ocupantes fizeram diversas plenárias e oficinas interativas com a comunidade, como sarau, feijoada, roda de samba, apresentação de maracatu, oficinas de teatro, além de debates políticos sobre a situação da educação do país, questões de gênero e etc.

Diversos agrupamentos políticos também apoiaram 0 ato dos discentes secundaristas, a exemplo da União Brasileira dos Estudantes Secundaristas (UBES) e ANEL (Assembleia Nacional de Estudantes - Livre). Isto gerou inúmeros debates nas diferentes unidades escolares.

Realizamos algumas entrevistas com lideranças e/ou alunos que se dispuseram e a partir das falas deles foi possível realizar diversas sínteses, sobretudo, no que se refere à construção de uma gestão democrática na escola.

Sobre as formas de organização é possível citar que as escolas tinham modelos similares de organizar as ocupações. Identificamos que os alunos se dividiram em comissões, responsáveis por tarefas específicas como comunicação, alimentação, atividades, entre outras.

Percebemos também que a ocupação estava sendo composta não somente por estudantes, mas recebendo o apoio de responsáveis de alunos, da comunidade escolar e estudantes até mesmo universitários. Em algumas escolas, foi possível 
identificar a participação de grupos políticos organizados como coletivos, união de estudantes e partidos políticos, estes últimos sendo minoritários.

As atividades realizadas eram definidas e demandadas pelos ocupantes, que, em geral, tinham predileção por debates e atividades culturais, em oposição ao clássico modelo de aulas expositivas. Sobre os temas, identificamos uma predileção por temas da atualidade (políticas públicas, sustentabilidade, ...), opressões (gênero, raça, LGBT), entre outros temas.

Entre as questões mais importantes constatadas, destacamos: a ebulição dos debates sobre feminismo, diversidade sexual e respeito às minorias; o protagonismo feminino nas atividades de liderança; a autogestão coletiva da ocupação; 0 questionamento do modelo de gestão escolar atual e a luta pela gestão democrática; questionamento sobre a democracia contemporânea e seus limites para a juventude; a identificação com a participação política; crítica ao sistema político partidário vigente; a identificação do espaço público como espaço a ser ocupado pela comunidade escolar; participação da comunidade escolar no cuidado com o espaço escolar e na definição dos usos desses espaços; reflexão sobre a necessidade de revisão do currículo, ampliando a possibilidade de se debater temas transversais e contemporâneos.

A seguir apresentamos mais algumas características das ocupações visitadas através dos dados gerados pela observação participante e pela coleta de dados on line. Logo depois apresentamos reflexões preliminares sobre algumas das categorias de conteúdo levantadas com base nas análises de discurso dos estudantes. Por fim, trazemos a contribuição da pedagogia militante para a formação humana dos sujeitos de pesquisa.

\section{DescreVEndo AS OCUPAÇões}

A metodologia que lançamos mão seguiu a respectiva ordem: contactamos as escolas, propusemos oficinas (de exibição de vídeos e posterior debate) e no ato da ida até as ocupações, nós dialogamos com alguns pais de alunos e com os discentes a respeito da ocupação, das pautas centrais, das dificuldades e necessidades, indagamos o que estava mudando na vida deles e o que os levou a compor o movimento.

Convidamos também para que respondessem espontaneamente os questionários ${ }^{4}$. Estes tinham como eixo verificar o papel do estudante na escola, o significado das ocupações para eles e seu conhecimento sobre a proposta constitucional de gestão democrática da educação prevista na Lei de Diretrizes e Bases da Educação Nacional (Lei 9.394/96). Indagamos sobre sua participação nos espaços de gestão democrática da escola e buscamos apreender suas representações sobre política e participação política, assim como seus es planos após a conclusão dos estudos na escola.

\footnotetext{
${ }^{4}$ Aplicamos o questionário com 17 estudantes.
} 


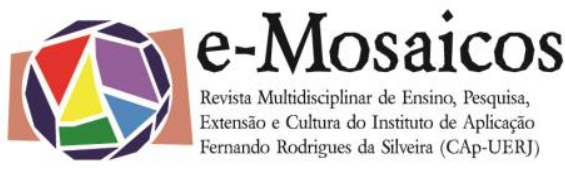

DOI: $10.12957 /$ e-mosaicos.2017.30265

Sobre as representações sociais, além dos questionários, investigamos através das páginas do movimento de ocupação das escolas do Rio de Janeiro que estavam disponíveis na internet. Por fim, entrevistamos algumas lideranças-chave (três ao total $^{5}$ ) das escolas. Comentaremos sobre estes aspectos neste tópico. A base teórica para entender essas representações foi o legado de Pierre Bourdieu (2011), no que tange sua discussão sobre o poder simbólico.

A representação envolve conhecimento e reconhecimento, e para entendê-las é preciso captar critérios objetivos de identidade regional, por exemplo. As representações também devem ser buscadas na prática social (ex: os dialetos, sotaques...) e são estes objetos de representações mentais, que significa aspectos de percepção e apreciação, de conhecimento e reconhecimento, em que os agentes investem seus interesses e pressupostos. Em outro pólo temos as representações de objetos, se baseia em coisas (emblemas, bandeiras...), - ou em atos, estratégias interessadas de manipulação simbólica, que têm em vista determinar a representação mental que os outros podem ter desta propriedade ou dos seus portadores (BOURDIEU, 2001).

Entendemos que Bourdieu apresenta um importante aporte teórico para esse estudo, pois sua perspectiva teórico-metodológica sobre o estudo das representações contempla a dialética materialista. Isso fica evidenciado em sua discussão sobre as estruturas estruturantes e estruturas estruturadas, por exemplo. Para este autor, os campos envolvem tensões que perpassam mediações econômicas, sociais, culturais e políticas, logo, a construção das representações está envolvida nesse espectro, e se interligam pelas categorias totalidade e particularidade (BOURDIEU, 2011).

Ao discutir as teorias dos Movimentos sociais, Gohn (1998) descreve que o paradigma dos Novos Movimentos Sociais mobilizam explicações que partem de aspectos conjunturais, envolve microprocessos da vida cotidiana e tem como categorias básicas a cultura, identidade, autonomia, subjetividade, interação política, cotidiano, representações e etc. Segundo a autora este paradigma tem forte influência da interpretação pós-estruturalista e pós-moderna da cultura e seria uma crítica ou discordância do paradigma marxista denominado de ortodoxo.

As análises sobre os movimentos sociais no Brasil estão pautadas em duas vertentes de discussões, quais sejam: uma primeira, voltada para descrição de casos empíricos e outra, menos frequente, que se dedica a análise teórica dos paradigmas dos Movimentos Sociais (GOHN, 1998). Este estudo se aproxima da primeira perspectiva citada, pois buscamos entender as manifestações destes fenômenos recentes do século XXI. O respaldo teórico dado por Gohn é pertinente neste estudo, pois localizamos no trabalho de campo pontos de convergência com o paradigma dos Novos Movimentos Sociais.

Para Santos (2005) os Novos Movimentos Sociais articulam pautas globais e locais, além de promover por vezes tensões no que diz respeito ao debate sobre cidadania e subjetividade. Para ele, por vezes, estes movimentos revelam uma

\footnotetext{
${ }^{5}$ Somente em uma das escolas, o Colégio Estadual Compositor Luiz Carlos da Vila, não foi possível realizar entrevista com uma jovem liderança.
} 
demanda de reivindicação de contemplação de aspectos subjetivos individuais meramente. Em outro pólo não é possível descartar que existe uma luta também por cidadania e direitos.

Entendemos que o objeto deste texto é mais diretamente voltado para pautas de cidadania, porém sem desprezar os aspectos subjetivos.

Sobre a relação global e local, as ocupações das escolas da rede estadual do Rio de Janeiro têm semelhanças com as rebeliões e ocupações de 2011 e 2013 . O ano de 2011 foi um marco importante internacionalmente, pois englobou desde a primavera árabe até as ocupações na Europa (na praça do sol, na Espanha, por exemplo) e EUA (movimento Occupy Wall Street).

Em 2013, o Brasil, desta vez, foi palco de movimentos parecidos, as chamadas Jornadas de Junho. Na ocasião, cidades do país inteiro registram milhares de pessoas nas ruas simultaneamente com as pautas das mais diversas possíveis - a exemplo do fim da corrupção, até a posição contrária a Proposta de Emenda Constitucional 37/20116.

Carneiro (2012) entende que o ano de 2011 tinha como pano de fundo uma crise social, econômica e financeira muito grande, se desdobrando na ação dos movimentos que contestavam as lideranças sindicais vigentes e contra as estruturas político partidárias (de direita ou de esquerda), mas sem forjar uma proposta de ruptura ou que construísse uma agenda de transformação a curto, médio ou longo prazo, embora na África tenham ocorridos movimentos revolucionários que derrubaram ditaduras de décadas. Na Espanha e Grécia também foram construídas alternativas políticas contra-hegemônicas.

Já Nogueira (2013) analisa que o ano de 2013 revelou ao Brasil uma crise profunda de representatividade e de legitimidade. Algo que era adormecido na sociedade civil brasileira, de repente se apresenta espontaneamente e intensamente como consensual.

As ocupações nas escolas que aqui discutimos seguiram essa tendência, pois foi oriunda de uma grave crise (tanto política, quanto econômica) do estado do Rio de Janeiro, repercutiu em categorias tradicionalmente organizadas como os educadores, que fizeram greve e diversos protestos, mas se desdobrou em atos protagonizados por jovens estudantes secundaristas.

Os discentes se solidarizaram com o movimento grevista dos educadores e construíram também sua pauta própria, marcando especificidades que demandam uma reflexão, pois revelam o gene da nova sociabilidade que emerge e que precisa ser entendida com as "lentes" do seu tempo e não necessariamente e somente com as do passado.

Apresentamos algumas das representações discentes que mais se destacaram. São trazidas, sintetizadas através das categorias de conteúdo exibidas a seguir.

\footnotetext{
${ }^{6}$ A PEC propunha que fosse incluído um novo parágrafo na Constituição Federal no qual a tarefa de investigação de infrações penais seria da alçada exclusiva da Polícia Federal e civis dos estados.
} 
DOI: $10.12957 /$ e-mosaicos.2017.30265

\section{Protagonismo feminino nas ATIVIDADES de LIDERANÇA E A EBULIÇÃo doS DEBATES SOBRE FEMINISMO, DIVERSIDADE SEXUAL E RESPEITO ÀS MINORIAS}

Em todas as unidades escolares visitadas identificamos uma quantidade expressiva de mulheres participando dos movimentos, assim como liderando esses coletivos. Das quatro escolas visitadas e analisadas, três delas tinham mulheres como vanguarda do movimento. Entendemos que esta sintonia tem relação muito estreita com a ascensão dos debates sobre gênero que hoje ganham muito espaço nas redes sociais e nas ruas das metrópoles brasileiras.

Também pudemos verificar que algumas lideranças femininas ganharam importância no cenário nacional através da difusão de seus posicionamentos através de postagens e vídeos compartilhados on line e também noticiados na mídia.

As jovens lideranças apresentavam uma habilidade e dedicação intensa com as tarefas da militância nas escolas. Era recorrente que a delegação de tarefas por elas fosse acompanhada da necessidade de se pensar as relações de gênero no espaço. Como exemplo, foi possível identificar que o modo de organização das tarefas nas ocupações buscava superar a atribuição de tarefas culinárias ou de limpeza a mulheres e essas eram distribuídas de modo igualitário independentemente do gênero.

O feminismo foi entendido pelos estudantes como um tema que deveria ser abordado transversalmente no projeto pedagógico. Dessa forma, vários eram os debates sobre o papel histórico da mulher na sociedade, sobre a reprodução e manifestações do machismo e patriarcado. Essa prática confronta diretamente propostas conservadoras do congresso brasileiro, onde alguns parlamentares vêm defendendo um projeto que negligencia debates dessa ordem através da chamada "escola sem partido".

Reconhecemos que entre os temas mais debatidos nas atividades de ocupação estão as questões de gênero, o feminismo em suas diversas vertentes (negro, classista) e as questões LGBT. Esses temas, conforme já foi apontado, são temas demandamos e construídos pelos estudantes.

Pautas como o respeito às diferenças, repúdio a atitudes LGBTfóbicas ou machistas eram recorrentes nas conversas informais e nos espaços deliberativos dos estudantes. Esses debates demonstraram reverberar não somente enquanto aconteciam, mas também na vida e na prática dos ocupantes. Vejamos a fala de aluno de uma das escolas ocupadas publicada em rede social:

Gente, eu vim falar sobre uma experiência que estou tendo com a minha escola Ocupada, Está tendo vários debates sobre questão de gênero, e Sobre Homofobia e Feminismo! está sendo tão gratificante participar disso! Então, Eu comprei um Bottom com a Bandeira LGBT e eu sempre ando com ele preso na blusa do lado onde o coração fica, que significa que eu tenho orgulho pelo o que luto, não luto só por essa causa e por outras que são necessárias como racismo, feminismo e etc... Hoje na escola um cara super simpático fez uma entrevista 
falando o que era ocupação, e eu falei tudo! e depois ele falou a respeito sobre o meu Bottom, e eu comecei a falar a respeito sobre LGBTFOBIA, Foi tão maravilhoso! Muita gente olha para mim no meio da rua andando com um Bottom LGBT $\mathrm{Na}$ blusa, eu não acho estranho! Eu sempre vou lutar, dependendo dos obstáculos que aparecer! Tivemos aulas de teatro e eu coloquei em prática a opressão sobre ser Gay, e foi Tão maravilhoso! Eu vou lutar até onde eu está em um negócio que se chama caixão! Além disso! Pode Reclamar Porque vou Lutar para ter Educação na escola e Colocar nessa Luta, Questões sobre Direito Igualitário! Se nós alunos ocupando escolas, estamos fazendo uma reviravolta, imagina colocar questões igualitárias nisso? Vai ser maravilhoso! <3 Não tenho medo de lutar e muito menos de mostrar quem eu sou, e que nesse mundo vim para lutar. (grifos nossos)

Os estudantes demonstraram que esses temas são de suma importância na sua formação enquanto sujeitos históricos e defenderam que eles deveriam estar pautados no currículo escolar. Essa compreensão nos remete a outra categoria muito presente nos discursos analisados: a necessidade de revisão do conteúdo curricular.

\section{REFLEXÃO SOBRE A NECESSIDADE DE REVISÃO DO CURRÍCULO, AMPLIANDO A POSSIBILIDADE DE SE DEBATER TEMAS TRANSVERSAIS E CONTEMPORÂNEOS}

A necessidade de revisão do conteúdo abordado nos currículos da educação básica brasileira foi muito claramente explicitada não somente nos discursos dos jovens militantes, mas em suas práticas no processo de organização das atividades de ocupação. Os estudantes demonstraram interesse e necessidade de se apropriar de conteúdos que, segundo eles, não estão contemplados nos temas tratados na escola.

Além das diversas dificuldades estruturais que fazem parte das pautas especificas de cada escola, e que notoriamente são fatores dificultadores do processo de aprendizagem - como falta de professores, de material escolar, de alimentação escolar, má gestão dos recursos na escola, entre outras coisas - foi possível perceber que engessamento dos currículos também se configura como um fator de desinteresse dos estudantes para com a escola.

Os próprios jovens relatam que não se percebiam interessados nas aulas tradicionais oferecidas em sua escola do mesmo modo como se viram interessados pelas atividades de aulas, debates ou rodas de conversa promovidas por professores apoiadores das ocupações.

\section{A IDENTIFICAÇÃo COM A PARTICIPAÇÃo POLÍTICA}

Os estudantes participantes das ocupações visitadas, em sua maioria com nenhuma experiência pregressa de organização e participação política, se mostraram 
muito identificados a militância. Foi muito comum identificarmos na fala dos mesmos uma identificação com a luta coletiva, com a construção democrática dos processos e de uma continuidade na atuação, compreendendo que a ocupação não se encerra em si mesma. A minoria já participou de grêmio estudantil ou até mesmo dos conselhos de classe da escola.

Em muitas escolas ocupadas pudemos verificar a criação ou reativação de grêmios estudantis; a construção de espaços coletivos deliberativos como assembleias gerais; a efetiva participação do estudante nos espaços deliberativos da escola.

Notamos, por meio das observações, que a escola que fica numa região mais próxima ao centro da capital fluminense (a Compositor Luiz Carlos da Vila), tinha mais agrupamentos políticos de diversos partidos e entidades que estavam presentes para construir a luta conjuntamente ou disputar a direção política. Já as demais escolas, mais distantes tanto do centro do Rio de Janeiro, quanto mais longe da capital, tinham direções políticas do processo mais homogêneas.

Nas duas escolas da capital fluminense, a preocupação dos estudantes com uma luta autônoma, sem muita interferência das entidades ou partidos era latente. No Colégio Compositor Luiz Carlos da Vila existiam cartazes que defendiam uma posição política do movimento de forma independente.

Poucos estudantes abordados durante as visitas (principalmente as lideranças) afirmaram ter mais interesse por política depois da participação nas ocupações e entenderem que sua participação na ocupação o transforma enquanto sujeito histórico. Uma maioria, porém, questionou bastante o modelo político vigente.

Entendemos que essa constatação é um paradoxo interessante, pois quase a unanimidade dos estudantes que responderam o questionário, disseram que acham a política inútil ou algo inóspito. Isso se evidencia em algumas frases usadas pelos estudantes, como: "acho uma coisa superficial", é "uma enrolação a nós humanos". Em todo caso, também encontramos respostas como "Deveria ser mais justa e honesta".

Ou seja, eles não viam a ocupação feita por eles como uma atividade política. Ao que tudo indica, tomaram a política como algo voltado para o status quo, nos moldes da política partidária representativa.

Tivemos a oportunidade de conversar com uma docente do Colégio Dom Pedro II e o relato dela indicou que alunos que antes eram tidos como pouco interessados nos estudos e nas demais atividades da escola, se tornaram lideranças nas ocupações. Ela ressaltou que diversos desses jovens eram estereotipados, pois apresentavam uma estética "mais alternativa" em relação à concepção estética" predominante na escola. Por vezes, eram alunos também que optavam por orientações sexuais não heteronormativas e isso juntamente era um fator desencadeador de preconceito.

\footnotetext{
${ }^{7}$ Vários alunos ocupantes usavam alargadores de orelha, pintavam o cabelo de variadas cores, como azul ou roxo.
} 
DOI: $10.12957 /$ e-mosaicos.2017.30265

A fala do aluno Nilson ${ }^{8}$ é significativa no que se refere ao que foi descrito. Perguntamos se o movimento de ocupações trouxe alguma mudança na relação dele com a escola e se mudou algo na vida dele em relação à participação política, ele afirmou que sim, houveram mudanças na vida e ele entende que houve "redução de preconceitos".

Falas como a de Lucas apontam que a participação política é importante, pois segundo ele: "Eu percebi que minha opinião sim é importante para poder mudar a sociedade e os locais em que vivemos". Sobre o mesmo assunto Fernando diz: "eu aprendi que 'a união faz a força', nós jovens juntos podemos mudar o ensino e até mais coisas". Novamente o paradoxo já descrito anteriormente se revela no questionário de Fernando, pois ele afirmou que não se interessa por política.

Simone não respondeu o que achava sobre a política, mas a respeito da pergunta sobre a participação ponderou: "aprendi que as mudanças acontecem com a participação política".

Entrevistamos a liderança do Instituto Rangel Pestana (em Nova Iguaçu) e Lilian demonstrou que entrou na ocupação por se sentir provocada a saber o que ocorria. Antes de se engajar ela leu sobre o assunto e se convenceu de que era importante construir essa luta.

Em uma passagem da entrevista de Lilian ela aponta uma dimensão histórica da ocupação, pois revela que aquele acontecimento não é uma luta só para essa geração é destinada também para outros estudantes que virão no futuro.

Dallari (1994) considera que é compreensível contradições como estas expressas pelos discentes, porém ele ajuda-nos a pensar sobre o quão fundamental a política é na nossa vida. Entendemos que as expressões dos discentes sejam parte da construção pedagógica deles sobre a vida política. Conforme já sinalizamos, a maioria dos estudantes com os quais conversamos sinalizou ser a primeira vez que faziam alguma atividade de mobilização coletiva.

É importante considerar que além dessas manifestações, em praticamente todas as 68 escolas que foram ocupadas na época ocorreu também um enfrentamento com o movimento chamado de desocupa. Este foi um movimento de estudantes contrários à ocupação e que reivindicavam o retorno imediato das aulas. Durante todo o período a tensão entre ambos os movimentos foi grande.

Xavier, uma das lideranças entrevistadas, ponderou que o movimento desocupa não tem dimensão que este ato é importante para os filhos deles, logo não podemos pautar somente o retorno imediato das aulas se a escola pode continuar na situação de dificuldade elevada que se encontra hoje. Não conseguimos entrevistar alunos apoiadores do desocupa.

\footnotetext{
${ }^{8}$ Todos os nomes de alunos citados são fictícios e foram alterados para garantir o sigilo ético necessário à pesquisa.
} 
DOI: $10.12957 /$ e-mosaicos.2017.30265

\section{A AUTOGESTÃo COLETIVA DA OCUPAÇÃo}

Observamos que a autogestão foi uma característica crucial de todas as escolas ocupadas. A descentralização e distribuição democrática de tarefas foi fundamental para a longa e consistente duração das ocupações. As tarefas eram definidas diariamente em assembleias. Por vezes ocorria mais de uma assembleia por dia, a depender da demanda e das tensões políticas e organizativas do dia.

De forma parecida com as manifestações de 2013 no Brasil, a descentralização e a organização por meio das redes sociais era algo muito intenso. Outros estudos têm demonstrado a importância das redes sociais nas mobilizações e como veículo de difusão de informações importantes para os movimentos. Todas as escolas visitadas mantinham páginas das ocupações no facebook e buscavam manter essas páginas atualizadas com as atividades e informações relevantes sobre a ocupação. Também verificamos que as redes sociais configuravam um espaço de contato com apoiadores das ocupações e com outras escolas ocupadas, numa troca de experiências e apoio mútuo. Isso se desdobrou em visitas de estudantes de diferentes escolas entre si, em assembleias interescolas e em mobilizações conjuntas como participação em audiência com o poder público.

Algumas lideranças surgiram de forma espontânea, seja pela afinidade com as atividades demandadas (como cozinhar, preparar cartazes, limpar a escola, reformar a quadra e etc.) ou por uma identidade com a construção coletiva dos trabalhos. Entendemos que nesse último caso há um processo que se assemelha com o que aponta Gramsci (1986) ao ponderar sobre a formação de intelectuais orgânicos e a organização da cultura, que partem do senso comum e elevam a sua consciência de classe. Neste movimento os intelectuais ajudam também toda a classe.

Gramsci discute a formação de partidos políticos, a organização do operariado, a construção de guerra de movimento e de posição, assim como a construção da revolução. Esses não foram temas das ocupações dos estudantes, mas as devidas similaridades podem ser aqui registradas.

Líderes entrevistados disseram que pela primeira vez se sentiam sujeitos ativos na escola, pois agora tinham voz e antes ninguém queria escutá-los ou achavam que o jovem não teria muito o que contribuir com a gestão da escola, com conteúdos pedagógicos ou outras atividades.

Em uma das escolas (Paulo Freire), a presença de alguns pais foi notada com muita veemência. Vimos pais levando os alunos para as ocupações, o que revelava um consentimento e apoio ao movimento. Entrevistamos dois responsáveis por um aluno que atuavam na ocupação periodicamente e prestavam apoio aos discentes, sem interferir na autonomia deles.

Uma das alunas desta mesma escola com a qual tivemos a oportunidade de conversar, relatou que seu o pai percebeu a diferença no comportamento da filha após a ocupação, ganhando mais responsabilidade e, por isso, entendia que ela poderia participar mais do processo. 
DOI: $10.12957 /$ e-mosaicos.2017.30265

Em todas as escolas os discentes revelavam que a escola agora estava mais limpa e organizada do que antes da ocupação.

Um aluno da CE Paulo Freire respondeu do seguinte modo quando perguntamos sobre a importância da ocupação na vida dele e se ela mudou algo desde então: "Mudou muita coisa, porque eu tenho mais tarefas e assim mais responsabilidades".

A autogestão do trabalho pedagógico é uma categoria considerada das mais importantes para Pistrak (2000), pois ele a considera como sendo fator-chave de uma pedagogia socialmente engajada e transformadora. No interior da escola, a autogestão mobiliza mediações fundamentais com sentido político-cultural significativos.

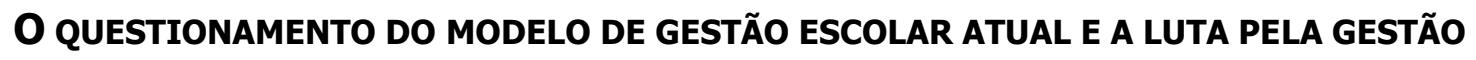 DEMOCRÁTICA}

Apesar de ser prevista na constituição e na LDB, a gestão democrática nas escolas ainda é um sonho na maioria das escolas brasileiras, que sofrem com processos exógenos, com a escolha de diretores vindas das secretarias de educação ou por indicação política das mais diversas. (PARO, 1998).

Dos 17 questionários aplicados em cinco somente obtivemos respostas negativas quanto ao conhecimento dos discentes sobre o que é gestão democrática na escola e o que eles pensavam sobre o assunto. Destacamos as respostas a seguir: "Já ouvi falar desde muito, porém não era posto em prática, 'hoje 'estamos (alunos) começando a ser ouvidos" (Sara). "Eu luto a favor, pois sou aluno de uma escola ocupada, onde reivindicam a democracia total" (Ricardo).

A liderança entrevistada na escola Dom Pedro II apontou que acha a escola chata, portanto os estudantes precisavam ser ouvidos para pensar coletivamente a gestão do espaço, formular currículo e etc.

Duas escolas iniciaram processos de eleição direta para diretores, o que evidenciou um triunfo importante das ocupações. As escolas foram a CE Dom Pedro II (em Petrópolis) e CE Paulo Freire (subúrbio do Rio de Janeiro). Acompanhamos essas notícias por meio das redes sociais e dos contatos que mantivemos com os alunos das escolas.

Os questionários também apontaram para a crítica ao modelo de gestão unilateral predominante nas escolas brasileiras.

Como foi descrito anteriormente, a possibilidade de fazer uma ocupação (ou seja, fazer uma democracia estudantil radicalizada na escola) viabilizou uma experiência pouco comum para a maioria dos jovens brasileiros. 
DOI: $10.12957 /$ e-mosaicos.2017.30265

Considerando outras questões relacionadas às ocupações, também, temos uma manchete ${ }^{9}$ que indica que escolas de São Paulo que foram ocupadas contra o projeto chamado de "reorganização escolar" tiveram notas acima da média no Exame Nacional do Ensino Médio (ENEM).

\section{RefLEXÕes SOBRE UMA PEDAGOGIA MILITANTE}

Encontramos nas propostas de Pistrak (2000) fundamentação teórica relevante o suficiente para estabelecer links de afinidade sobre as representações dos discentes e o que teóricos da educação têm a contribuir com o tema dessa pesquisa.

O autor escreve em um contexto da Revolução Russa, que, no campo da educação, exigia uma formação humana voltada para a desalienação, a busca de um bem comum em contraposição ao individualismo. Na visão de Pistrak esses objetivos não poderiam ser alcançados através das velhas formas pedagógicas, ainda que com novos conteúdos. Ele identificava que isso seria insuficiente para uma época revolucionária e, portanto, se fazia necessário propor uma mudança radical na estrutura da instituição escolar. Nesse sentido, sentimos a necessidade de recorrer ao autor para dialogar com as formas de reivindicação de transformação apontadas pelos estudantes ocupantes, mesmo entendendo que os contextos históricos, sociais e políticos que pesquisamos são completamente diferentes.

Pistrak desenvolveu sua Escola do Trabalho fugindo dos meros ajustes ao que já existiam e buscando então, fundar algo novo frente aos desafios do tempo vivido. Fez isso com base nas leis gerais que regem o conhecimento do mundo natural e social, a preocupação com o social, a preocupação com o atual, as leis do trabalho humano, os dados sobre a estrutura psicofísica dos educandos, o método dialético que atua como uma força organizadora do mundo.

Entre as questões que podemos destacar na escola pensada por Pistrak estão: a necessidade de desenvolver a criatividade pedagógica no professor; a compreensão das questões do espaço escolar à luz do método dialético; a dimensão política do trabalho pedagógico; a auto-organização dos jovens;

A Escola do Trabalho é, portanto, concebida por Pistrak não como uma escola marxista, mas como resultado de uma prática pedagógica, ou seja, a sistematização de uma experiência concreta. Nesse sentido ela é concebida como um instrumento que capacita o homem a compreender seu papel nas lutas sociais (localizando a classe trabalhadora nessa luta contra as estruturas capitalistas). Assim, o processo pedagógico precisa ser organizado de modo histórico e condizente com a realidade do tempo em que se insere. Isso porque para Pistrak o estudo da realidade histórica está diretamente ligado com a localização do espaço em que o jovem se insere nas disputas e lutas travadas no mundo e, portanto, o conteúdo de ensino deve ter por objetivo instrumentalizar o estudante para a construção de uma nova sociedade.

\footnotetext{
${ }_{9}$ Disponível em: http://www.brasilpost.com.br/2016/10/06/mec-exclui-institutos_n_12376874.html . Acesso em: 20 de dezembro de 2016.
} 
DOI: $10.12957 /$ e-mosaicos.2017.30265

Outro aspecto importante apontado pelo autor, é o princípio de autoorganização dos alunos, já bastante frisado por nós. Esse princípio está intimamente ligado com o desenvolvimento de qualidades a realidade atual, como "[...] 1) aptidão para trabalhar coletivamente e para encontrar espaço num trabalho coletivo; 2) aptidão para analisar cada problema novo como organizador; 3 ) aptidão para criar as formas eficazes de organização" (PISTRAK, 2000, p. 41).

No entanto, Pistrak nos dá as pistas sobre as formas de desenvolvimento dessas aptidões, quando assume que as mesmas se adquirem na prática, no próprio trabalho coletivo, alternando posições, entre situações de liderança, execução de tarefas, cooperação, entre outras.

É preciso reconhecer de uma vez por todas que a criança e, sobretudo, o adolescente, não se preparam apenas para viver, mas já vivem uma verdadeira vida. Devem consequentemente organizar esta vida. A auto-organização deve ser para eles um trabalho sério, compreendendo obrigações e sérias responsabilidades. Se quisermos que as crianças conservem o interesse pela escola, considerando-a como seu centro vital, como sua organização, é preciso nunca perder de vista que as crianças não se preparam para se tornar membros da sociedade, mas já o são, tendo já seus problemas, interesses, objetivos, ideais, já estando ligadas à vida dos adultos e do conjunto da sociedade (PISTRAK, 2000, p. 42-43).

Para que a Escola do Trabalho venha a responder aos anseios de Pistrak por uma escola que seja educadora do povo, com o povo e para o povo, no sentido de responder a suas questões, ela precisa conjugar os diversos aspectos da vida das pessoas. Assim, uma das contribuições nesse sentido é o rompimento com a ideia de uma pedagogia centrada no conteúdo, avançando para uma prática pedagógica construída com os jovens organizada através da ação.

Se a auto-organização das crianças na escola soviética não se basear na existência do coletivo infantil, será uma disposição abortiva. Mas, perguntará o leitor, qual é a escola "onde não há coletivo Infantil". Isso é verdadeiro, se considerar o coletivo como reunião acidental de uma certa quantidade de crianças num mesmo lugar visando à formação, isto é, visando a algo que se refere apenas ao aspecto exterior de suas preocupações, um objetivo que não exprime ainda o interesse infantil. Mas uma certa quantidade de crianças, um simples agrupamento quantitativo, uma reunião acidental, não formam ainda um coletivo (PISTRAK, 2000, p.176-177).

Consideramos ainda que as ocupações estudantis têm se configurado como um espaço privilegiado para a participação política de jovens mulheres militantes e 
para a construção de outras formas de sociabilidade que busquem a superação das relações de opressão de gênero historicamente construídas, dentre outras questões. Nesse sentido, o engajamento político neste tipo de movimento possibilita às mulheres maior visibilidade da luta feminista e a busca pela transformação dessas relações através da construção de relações mais equânimes e democráticas no espaço escolar.

De Pistrak extraímos também a lição de que esta pedagogia militante se manifesta na escola e expande para outras dimensões da vida. Este processo tem caráter sobretudo prático. A pedagogia militante no nosso entendimento envolve esse aspecto dialético, de práxis entre o fazer (lutar), transformar, construir novas sínteses sobre a sua realidade. Gramsci (2001) e Freire (1987) também ajudam a ponderar sobre essa perspectiva.

Como autores da sociologia reconhecem, a escola é um espaço de suma importância para a socialização das gerações futuras. (DURKHEIM, 1965; ALTHUSSER, 1996). Porém dentro desse contexto há espaços inúmeros para a disputa de projetos de sociedade e de concepção de sujeito (MÉSZÁROS, 2005).

\section{CONSIDERAÇões FinaIS}

Excelente a forma radical que os estudantes se manifestaram através da ocupação e somente assim que nós somos ouvidos.

Mudou muito a forma como via a escola e a política. Passei a ter uma relação de mais carinho e admiração pela escola e ser mais politizada (Daiane)

Verificamos, por meio dos discursos dos discentes fluminenses, que as experiências políticas vividas foram significativas para estes sujeitos, na perspectiva da construção da identidade coletiva, da participação política, da centralidade do protagonismo jovem organizado e descentralizado e, por conseguinte, de seu engajamento como sujeitos históricos, que através de uma pedagogia militante encontram sentido na formação escolar. As epígrafes de uma aluna participante da pesquisa apontam nessa direção.

Os discentes estão conseguindo promover debates fundamentais tanto nas escolas quanto na sociedade brasileira como um todo. Nas escolas verificamos triunfos como as eleições diretas para diretores, além de elevação da politização dos discentes e redimensionamento do debate pedagógico nas escolas. Estudos futuros ainda precisam ser feitos para acompanhar os desdobramentos das ocupações de 2016.

Não foi possível identificar a opinião dos jovens agora ex-ocupantes sobre as propostas recentes de reforma do ensino médio (MP 746/2016) ou do projeto Escola 
Sem Partido, pois foram questões inseridas na agenda política após o movimento estudado.

Indagações como: o que pensarão os jovens ocupantes sobre política e participação política daqui há três anos (quando a maioria acabar o ensino médio)? Qual serão as representações deles sobre os temas levantados de forma inédita até então nas suas vidas? A educação estará fazendo algum sentido para promoção de perspectivas futuras para esses alunos? Esses são alguns exemplos de perguntas ainda em aberto.

Compreendemos que essa pedagogia militante se relaciona com a afirmação do autor soviético Pistrak (2000) que sugere que a educação, e por conseguinte o próprio espaço escolar de formação, faz sentido uma vez que os sujeitos que atuam nela sejam engajados com o ato pedagógico, tenham uma reflexão sobre o contexto histórico social, cultural e econômico vigente e possam contribuir com a transformação de um projeto histórico transformador. A juventude que dialogamos aponta para esses aspectos.

Retratamos a fala de Mário, pois entendemos que é uma grande síntese da perspectiva de pedagogia militante. Ao ser perguntado sobre por que acha importante o movimento de ocupação das escolas do Rio de Janeiro, e ele afirmou "Para os estudantes terem voz ativa na sociedade".

Dialeticamente a citação do estudante mobiliza dimensões que vão do particular ao geral, uma vez que para ele a participação política na escola é pedagógica no espaço escolar, pois dá voz ativa ao estudante (ou seja, sujeito com identidade coletiva claramente definida), mas que isso é um passo importante para a transformação da sociedade (aspecto de totalidade).

Entendemos também que as representações dos discentes, por vezes, apresentaram manifestações contraditórias, o que não quer dizer que não haja coerência no que eles expressaram. Faz-se necessário contextualizar o momento histórico atual de extrema descrença com a política, portanto os discentes traduzem isso. Compreendemos também que isso é próprio da pouca experiência política deles. Porém, a valorização à política, ainda que indiretamente, esteve sempre latente.

Mobilizando Gohn (1998), estas características tornam a análise dos Novos Movimentos Sociais bastante desafiadoras, pois são contraditórias as suas manifestações.

Estamos envolvidos pelo desafio de entender o que os jovens que se organizam e protagonizam movimentos de vanguarda têm a dizer.

Apontamos como extremamente relevante a ascensão de bandeiras contrahegemônicas que vão de encontro à lógica ainda predominante da velha política brasileira, expressa sobretudo na atual configuração do congresso nacional, que é elitista, majoritariamente masculino e conservador. Os jovens de hoje apontam para perspectivas bem diferentes dos resquícios do passado que insistem em se perpetuar. 


\section{REFERÊNCIAS BibLIOGRÁFICAS}

ALTHUSSER, Louis. Ideologia e Aparelhos Ideológicos de Estado (notas para uma investigação). In: ZIZEK, Slavoj (Org). Um Mapa da Ideologia. Rio de Janeiro: Contraponto, 1996.

BOURDIEU, Pierre. O poder simbólico. Rio de Janeiro: Bertrand Brasil, 2011. . Poder, derecho y clases sociales. Bilbao: Desclée de Brouwer, 2001.

CAMPOS, Antonia; MEDEIROS, Jonas; RIBEIRO, Marcio.Escolas de Luta. Coleção Baderna. São Paulo:Veneta, 2016.

CARNEIRO, Henrique Soares. Apresentação: rebeliões e ocupações de 2011. In: HARVEY, David (Et al.) Ocuppy. Movimentos de Protestos que tomaram as ruas. São Paulo: Boitempo, Carta Maior, 2012.

DALLARI, Dalmo. O que é participação política? São Paulo: Brasiliense, 1994.

DURKHEIM, Émile. Educação e Sociologia. São Paulo: Edições Melhoramentos, 1965.

EL PAIS. PEC 241: Com quase 1.000 escolas ocupadas no país, ato de estudantes chega a SP. Disponível em:

http://brasil.elpais.com/brasil/2016/10/24/politica/1477327658_698523.html. Acesso em 20 de dezembro de 2016.

FREIRE, Paulo. Pedagogia do oprimido. Rio de Janeiro: Paz e Terra,1987.

GLOBO. Ocupação de escolas e universidades chega a 19 estados. Bom dia Brasil: Edição do dia 26/10/2016. Disponível em: http://g1.globo.com/bom-diabrasil/noticia/2016/10/ocupacao-de-escolas-e-universidades-chega-19-estados.html . Acesso em 20 de dezembro de 2016.

GOHN, Maria da Glória. Teorias dos Movimentos Sociais- Paradigmas Clássicos e Contemporâneos.São Paulo: Edições LOYOLA, 1997.

GRAMSCI, Antonio. (1986) Concepção Dialética da História.Rio de Janeiro: Civilização Brasileira. Rio de Janeiro. 1986.

Cadernos do Cárcere, Vol. 2.Os intelectuais. O principio educativo. Jornalismo. Rio de Janeiro; Civilização Brasileira, 2001.

MÉSZÁROS, István. A Educação para Além do Capital. São Paulo: Boitempo Editorial, 2005. 
DOI: $10.12957 /$ e-mosaicos.2017.30265

NOGUEIRA, Marco Aurélio. As ruas e a democracia: ensaios sobre o Brasil contemporâneo. Brasília: Fundação Astrogildo Pereira (FAP); Rio de Janeiro: contraponto, 2013.

PARO, Vitor. A gestão da educação ante as exigências de qualidade e produtividade da escola pública. In: SILVA, Luiz Heron da (org.) $A$ escola cidadã no contexto da globalização. Petrópolis, Vozes, 1998.

PISTRAK, Moisey. Fundamentos da escola do trabalho.São Paulo. Expressão Popular, 2000.

SANTOS, Boaventura Sousa. Os novos movimentos sociais. In: LEHER, Roberto; SETÚBAL, Mariana. (Orgs.). Pensamento crítico e movimentos sociais. diálogos para uma nova práxis. São Paulo: Cortez, 2005. 